\title{
Conditions of Satisfaction of the Solar Control Box
}

\section{Constraints}

\author{
Khaoula RABOUDI ${ }^{1}$ and Abdelkader BEN SACI ${ }^{2}$ \\ 1. M2A Team, National School of Architecture and Urbanism, University of Carthage, Sidi Bou Saiid 2026, Tunisia \\ 2. Research Center on Sound, Space and Urban Environment, National Special School of Architecture, Grenoble 38000, France
}

\begin{abstract}
This paper develops an approach for the satisfaction of the Solar Control Box constraints. This is the volume conditioned by both the Solar Envelope rules and the Shading Envelope rules. The Solar Envelope defines the largest volume that does not cast its shadows on neighboring buildings during winter beneficial periods of sunshine. The Shading Envelope is the lowest volume to shade the neighboring buildings during summer overheating periods. The Solar Envelope and the Shading Envelope are respectively a maximal and a minimal limit of the Solar Control Box. This volume will serve as a medium to assist planners in drafting morphological urban rules of solar control. Our purpose here is to respond to the question: To what extent it would be possible to generate a volume respecting the two types of constraints (solar access and shading needs)?
\end{abstract}

Key words: Solar envelope, shading envelope, solar control box, urban rules.

\section{Introduction}

Urban densification is at the heart of the current debate in architecture and urbanism. Urban planners are faced with crucial decisions: How to respond to housing demand while meeting the sustainable development policies requirements? In this paper, we deal with issues upstream the project that is in the urban regulations formulation phase. Indeed, the different regulatory tools currently implemented are not adapted to this new reality. The main object of this research is to assist urban planners in the formulation process of morphological urban rules of solar control. The concept of solar control integrates both summer shading needs and winter solar access needs. This is to ensure an urban densification matching the climatic characteristics of each region.

This paper presents an approach for meeting the Solar Control Box constraints XB. This is the spatial delimitation of the volume conditioned by both the Solar Envelope rules and the Shading Envelope rules

Corresponding author: Khaoula RABOUDI, Ph.D., research field: morphology of architecture.
[1]. The Solar Envelope rules define the largest volume that does not cast its shadows on the neighboring buildings during winter beneficial periods of sunshine. The solar access problem has been treated by different studies [2-5]. Knowles [5] developed the Solar Envelope 30 years ago. The concept protects the solar rights in urban areas and at the same time is a useful instrument of urban planning [6-8]. The Shading Envelope rules define the lowest volume to shade the neighboring buildings during summer overheating periods. Several studies on city planning have shown the importance of shading to face the urban heat island phenomenon. However, these studies focus on the use of vegetation and sunscreens to protect buildings from the summer sun. We propose the concept of the Shading Envelope to protect buildings from excessive sun exposure by projecting mutual shading one on the other.

The Shading Envelope fixes indeed the limits of a minimal volume restricting the projection of undesirable summer solar radiation. The Solar Envelope fixes instead the limits of a maximal volume restricting winter shadows projection. These two 
concepts allow producing morphological urban rules of solar control. In this paper, we propose to explore the possibility of generating Solar Control Box solutions satisfying both the solar access and the shading rules. The purpose here is to design buildings respecting winter solar rights and summer shading needs.

\section{Solar Control Box Rules}

\subsection{Solar Envelope Rules}

The Solar Envelope rules, presented by Knowles [5], are the cut-off-time and the shadow fences. The cut-off-time is the period of insured solar access. It is calculated according to the sunshine needs of a specified region and it depends on the function of the surrounding buildings. We propose to base on the solar radiation (expressed in watts per square meter $\mathrm{W} / \mathrm{m}^{2}$ ) received by the vertical and horizontal surfaces of the buildings. The intensity of the solar radiation received allows identifying the periods of winter desirable solar peaks.

The shadow fences are the restricting limits for shadow projection. The proposed building must not project its shadows outside this limit [5].

\subsection{Shading Envelope Rules}

The Shading Envelope is controlled by two constraints: the cut-off-time and the solar fences [1].
We propose to distinguish between the shading cut-off-time for the Solar Envelope and the solar cut-off-time for the Shading Envelope. The solar cut-off-time is the period of time for which the shading is desirable. It is determined according to the shading needs of a specified region and it depends on the function of the surrounding buildings. The calculation of the solar radiation received by the vertical and horizontal surfaces of constructions allows determining undesirable periods of solar peaks in summer.

The solar fences are the limits within which the shading is desirable. They are a restricting limit for the penetration of undesirable sunshine in summer.

\section{Method for Generating the Solar Envelope}

We present here an application on a case of an isolated habitat parcel located in the city of Tozeur in the south of Tunisia (Fig. 2).

\subsection{Determination of the Shading Cut-off-time}

According to Knowles [5], shading cut-off-time $T_{\mathrm{o}}$ is calculated at the date of the winter solstice (December 21). We propose here to base on the weather data (minimum and maximum average temperatures) of the city of Tozeur to fix a period of desirable solar access (Table 1).

Table 1 Minimum and maximum average temperatures (degrees Celsius) in Tozeur (Tunisia).

\begin{tabular}{|c|c|c|}
\hline \begin{tabular}{|ll} 
Month & Average temperatures \\
\end{tabular} & Minimum temperature average $\left({ }^{\circ} \mathrm{C}\right)$ & Maximum temperature average $\left({ }^{\circ} \mathrm{C}\right)$ \\
\hline January & 6.3 & 16.7 \\
\hline February & 8.2 & 19.4 \\
\hline March & 10.4 & 22.3 \\
\hline April & 13.8 & 26.4 \\
\hline May & 18 & 31.2 \\
\hline June & 22.3 & 36.3 \\
\hline July & 24.8 & 39.1 \\
\hline August & 25.1 & 38.9 \\
\hline September & 22.2 & 34.4 \\
\hline October & 17 & 28.2 \\
\hline November & 11.1 & 21.7 \\
\hline December & 6.8 & 17.2 \\
\hline
\end{tabular}


In the city of Tozeur, the lowest minimum and maximum temperature average of the year is recorded in the month of January. We base on the date of the 1 st January to define the shading cut-off time. The calculation of the solar radiation received by the different orientations of the façades (South, North, East, West, Southeast, Southwest, Northeast, and Northwest) on January 1st allows generating the following curves (Fig. 1).

We propose to preserve solar access during the solar peak between $9 \mathrm{~h}$ and $15 \mathrm{~h}$. The shading cut-off-time of the Southeast and the Southwest façades for the studied case is then $T_{o}=[9 h, 15 h]$.

\subsection{Delimitation of the Shadow Fences}

Shadow fences are limited by the foot of the neighboring buildings facades receiving high levels of solar radiation in winter that is the Southeast and the Southwest façades (Fig. 2).

\subsection{Generation of the Solar Envelope}

We generate the Solar Envelope SE based on the method developed by Stasinopoulos [9] (Fig. 2).

\section{Method for Generating the Shading Envelope}

We propose to use the Shading Envelope concept to shade neighboring buildings façades during the overheating summer periods. We present here the Shading Envelope for the same case dealt with above.

\subsection{Determination of the Solar Cut-off-time}

For the shading envelope, the solar cut-off-time $T_{s}$ is defined by the hours of desirable shade. The highest

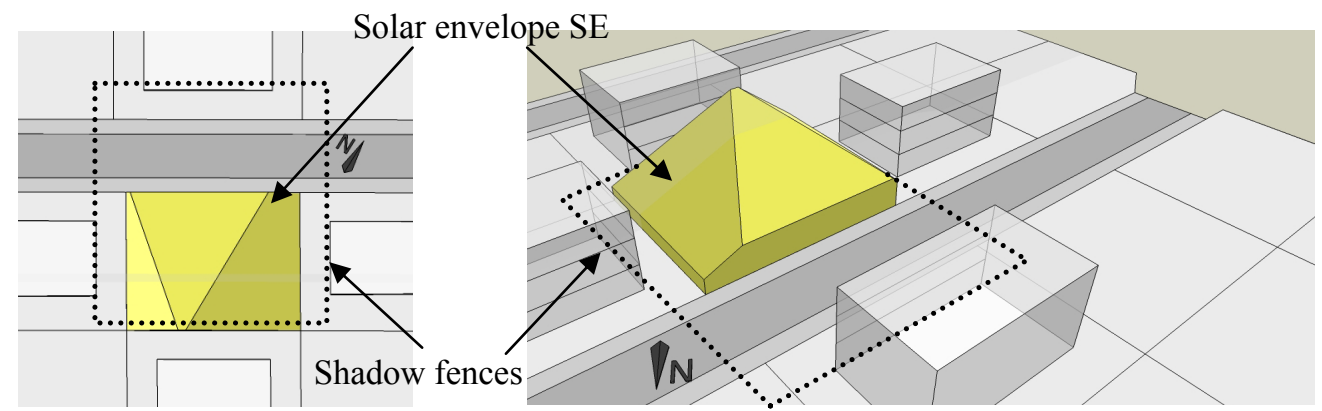

Fig. 1 Solar envelope SE ensuring solar access to the foot of neighboring buildings façades from $9 \mathrm{~h}$ to $15 \mathrm{~h}$.

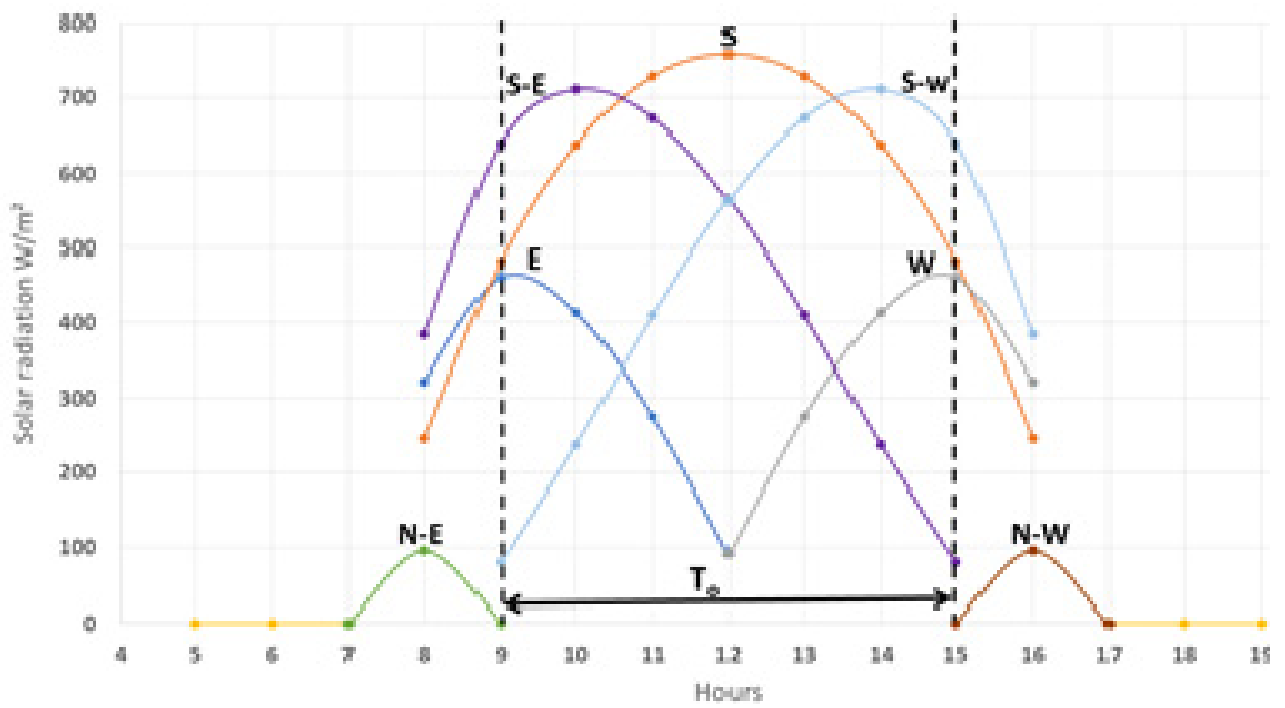


Fig. 2 Solar radiation $\left(\mathrm{W} / \mathrm{m}^{2}\right)$ curves received by South (S), North (N), East (E), West (W), Southeast (S-E), Southwest (S-O), Northeast (N-E) and Northwest (N-W) façades on January 1st at Tozeur.

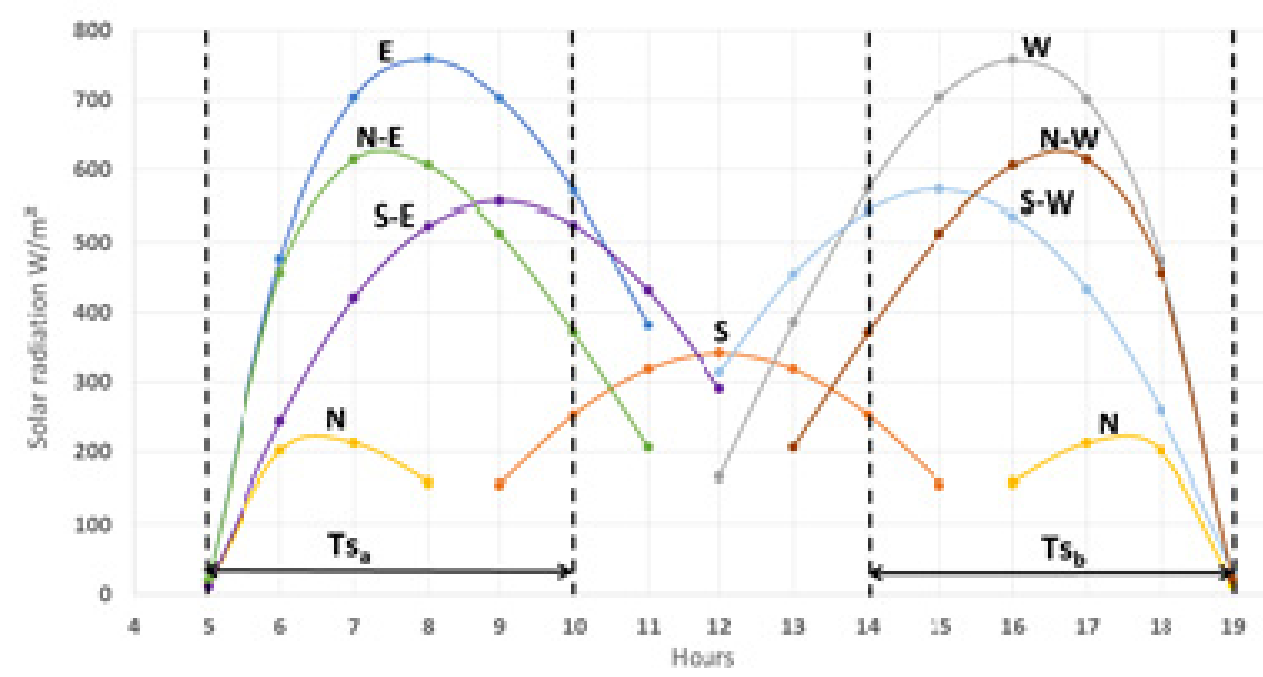

Fig. 3 Solar radiation $\left(W / m^{2}\right)$ curves received by South (S), North (N), East (E), West (W), Southeast (S-E), Southwest (S-W), Northeast (N-E) and Northwest (N-W) façades on July 1 st at Tozeur.

maximum temperature average of the year in the city of Tozeur is recorded in the month of July. The calculation of the solar radiation received by the different orientations of the façades (South, North, East, West, Southeast, Southwest, Northeast, and Northwest) at the date of July 1st allows generating the following curves (Fig. 3).

We propose to maintain the façades shaded during periods of solar peaks. The first period of solar peak is received by the Northeast and Southeast façades, it is between $6 \mathrm{~h}$ and $10 \mathrm{~h}$. A second period is received by the Northwest and Southwest façades, it is between 14 $\mathrm{h}$ and $18 \mathrm{~h}$. However, the solar geometry involves spreading the solar cut-off-time from sunrise until 10 $\mathrm{h}\left(\mathrm{T}_{\mathrm{sa}}\right)$ for the Northeast and Southeast façades and from $14 \mathrm{~h}$ until sunset $\left(\mathrm{T}_{\mathrm{sb}}\right)$ for Northwest and Southwest facades.

\subsection{Delimitation of the Solar Fences}

For the studied parcel, solar fences are limited by the highest level of buildings facades receiving significant solar radiation in summer. The shadow will reach this limit during the solar cut-off-time. The solar fences are thus limited by the Northeast, Northwest, Southeast and Southwest facades of neighboring buildings (Fig. 4).

\subsection{Generation of the Shading Envelope}

We use the geometric construction method of the Solar Envelope to generate the Shading Envelope. We thus proceed to construct the Shading Envelope with three main volumes (Fig. 5a). $\mathrm{Vt}_{\mathrm{sa}}$ and $\mathrm{Vt}_{\mathrm{sb}}$ are two volumes with a base defined by solar fences limit. These two volumes are extruded according to the sun paths directions relatively to the solar cut-of-time $T_{\text {sa }}$ $=10 \mathrm{~h}$ and $\mathrm{T}_{\mathrm{sb}}=14 \mathrm{~h}$. The third volume $\mathrm{V}_{\mathrm{c}}$ is extruded from the polygon forming the building plot. The Shading Envelope OE is then the intersection of the three volumes $\mathrm{Vt}_{\mathrm{sa}}, \mathrm{Vt}_{\mathrm{sb}}$ and $\mathrm{V}_{\mathrm{c}}$ :

$$
\mathrm{EO}=\mathrm{Vt}_{\mathrm{sa}} \cap \mathrm{Vt}_{\mathrm{sb}} \cap \mathrm{V}_{\mathrm{c}} \text { (Fig. 5b). }
$$

\section{Generation of the Solar Envelopes}

\subsection{Variation of the Shading Cut-off-time}

For the studied case, the shading cut-off-time $\mathrm{T}_{\mathrm{o}}=$ [9h, 15h] corresponds to a period of solar radiation peak of $6 \mathrm{~h}$. During this period, we can define different ranges of cut-off-time $(5 h, 4 h, 3 h .$.$) . Each selected$ time-range will have a different impact on energy consumption (for heating) of the construction in 
winter. We propose to define other shading cut-off-times during the solar radiation peak. We thus set the followings $\mathrm{T}_{\mathrm{o}}: \mathrm{T}_{\mathrm{o} 1}=[9 \mathrm{~h}, 15 \mathrm{~h}], \mathrm{T}_{\mathrm{o} 2}=[10 \mathrm{~h}, 14 \mathrm{~h}]$,

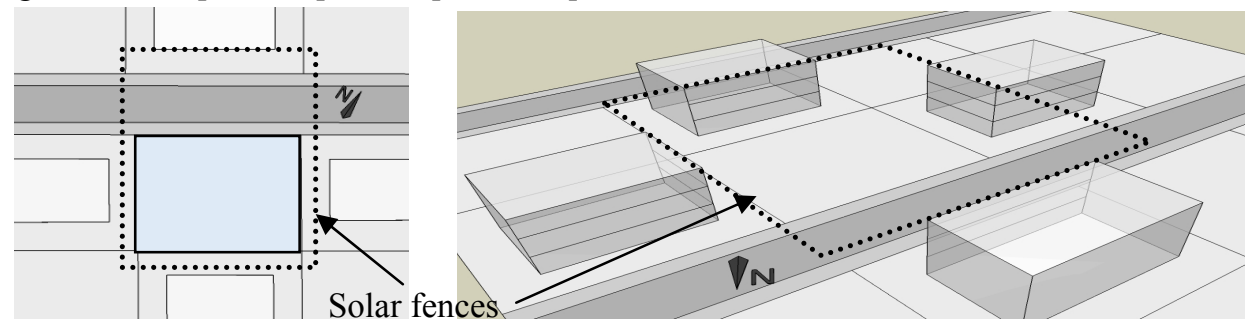

Fig. 4 Delimitation of the solar fences for an isolated habitat parcel located in Tozeur (Tunisia).

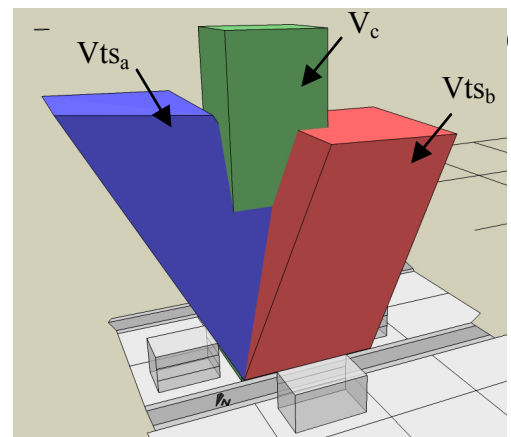

(a)

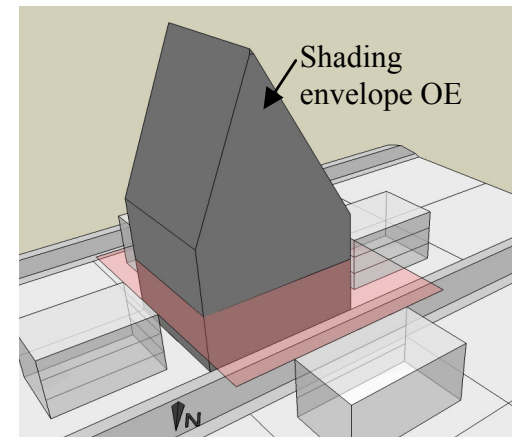

(b)

Fig. 5 (a) Volumes used in the construction of the Shading Envelope: $\mathrm{Vt}_{\mathrm{sa}}$ (according to the sun direction at 10h), $\mathrm{Vts}_{\mathrm{b}}$ (according to the sun direction at 14h) and $V_{c}$ (from parcel base); (b): Shading Envelope $E O=V t_{s a} \cap V t_{s b} \cap V_{c}$.

$\mathrm{T}_{\mathrm{o} 3}=[11 \mathrm{~h}, 13 \mathrm{~h}], \mathrm{T}_{\mathrm{o} 4}[11: 3012: 30]$

\subsection{Variation of the Shadow Fences Planes}

We propose the notion of shadow fences plane $\mathrm{P}_{\mathrm{co}}$. It is a limited zone of restricted shadow projection. We assign different levels of the shadow fences plane (Lvl.0, Lvl.1, ... Lvl.n) according to the need of solar access (presence or absence of openings on the facades) and to the function of the building. For the case studied here, we set shadow fences planes with an interval of a floor level (Lvl.0, Lvl.3m, Lvl.6m and Lvl.9m). The Lvl.0 of shadow fences plane is defined by the base of the facades of neighboring buildings receiving a high solar radiation in winter. Lvl.3m and Lvl.6m planes correspond to the intermediate floors of the neighboring buildings. Lvl.9m corresponds to the highest level of the neighboring buildings facades.

\subsection{Generation of the Solar Envelopes}

We proceed to the generation of the Solar
Envelopes corresponding to the shading cut-off-time constraints and shadow fences plane constraints defined above. Let $n$ be the shading cut-off-time constraints number and $m$ the shadow fences plane constraints number. The total number of Solar Envelope solutions, denoted $S$, is then calculated by the formula: $S=n * m$. We set 4 shading cut-off-time and 4 shadow fences plane. The number of Solar Envelopes generated in this case is 16 solutions (Fig. 6).

\section{Generation of the Shading Envelopes}

\subsection{Variation of the Solar Cut-off-time}

We set different time-range of solar cut-off-time during the undesirable solar peak in winter $T_{\mathrm{s}}=\{[5 \mathrm{~h}$, 10h] $\mathrm{U}[14 \mathrm{~h}, 19 \mathrm{~h} 40]\}$. Each selected time range implies different energy consumption (for air conditioning, ventilation...) of the construction in summer. We propose the following solar cut-off-time 
$\mathrm{T}_{\mathrm{s}}: \mathrm{T}_{\mathrm{s} 1}=\{[5 \mathrm{~h}, 10 \mathrm{~h}] \mathrm{U}[14 \mathrm{~h}, 19 \mathrm{~h} 40]\}, \mathrm{T}_{\mathrm{s} 2}=\{[5 \mathrm{~h}, 9 \mathrm{~h}]$

$\mathrm{U}[15 \mathrm{~h}, 19 \mathrm{~h} 40]\}, \mathrm{T}_{\mathrm{s} 3}=\{[5 \mathrm{~h}, 8 \mathrm{~h}] \mathrm{U}[16 \mathrm{~h}, 19 \mathrm{~h} 40]\}$,

$\mathrm{T}_{\mathrm{s} 4}=\{[5 \mathrm{~h}, 7 \mathrm{~h}] \mathrm{U}[17 \mathrm{~h}, 19 \mathrm{~h} 40]\}$.

\begin{tabular}{|c|c|c|c|c|c|}
\hline & & & Variation & hadow cut-off-time & \\
\hline & & $\mathrm{T}_{\mathrm{ol}}=[9 \mathrm{~h}, 15 \mathrm{~h}]$ & $\mathrm{T}_{\mathrm{o} 2}=[10 \mathrm{~h}, 14 \mathrm{~h}]$ & $\mathrm{T}_{\mathrm{o} 3}=[11 \mathrm{~h}, 13 \mathrm{~h}]$ & $\mathrm{T}_{\mathrm{o4}}=[11 \mathrm{~h} 30,12 \mathrm{~h} 30]$ \\
\hline & Lvl.0m & $\mathrm{V}=2,148.88 \mathrm{~m}^{3}$ & $\mathrm{~V}=3,549.82 \mathrm{~m}^{3}$ & $\mathrm{~V}=4,899 \mathrm{~m}^{3}$ & $\mathrm{~V}=5,631.06 \mathrm{~m}^{3}$ \\
\hline $\begin{array}{l}\text { Variation of } \\
\text { the shadow }\end{array}$ & Lvl.3m & $\mathrm{V}=345992 \mathrm{~m}^{3}$ & $\mathrm{~V}=4.86086 \mathrm{~m}^{3}$ & $V_{\mathrm{V}=6210}$ & $\sum_{V=60421 m^{3}}$ \\
\hline & Lvl.6m & & & & \\
\hline & Lvl.9m & & & & \\
\hline & & $\mathrm{V}=6,081.99 \mathrm{~m}^{3}$ & $\mathrm{~V}=7,482.93 \mathrm{~m}^{3}$ & $\mathrm{~V}=8,832.11 \mathrm{~m}^{3}$ & $\mathrm{~V}=9,564.17 \mathrm{~m}^{3}$ \\
\hline
\end{tabular}

Fig. 6 Generation of the solar envelopes for an isolated habitat parcel located in Tozeur (Tunisia).

\subsection{Variation of the Solar Fences Planes}

We attribute to the solar fences planes the same levels of the Shadow fences planes (Lvl.0, Lvl.3m, Lvl.6m and Lvl.9m). Each plane level can be set according to the need of shading and to the neighboring buildings function. The Lvl.9m in this case corresponds to the highest level of neighboring buildings facades that receive significant solar radiation in summer, that is to say, the Northeast, Northwest, Southeast and Southwest facades.

\subsection{Generation of the Shading Envelopes}

We proceed to the generation of the Shading Envelopes within the constraints of solar cut-off-time and solar fences planes set earlier. The total number of Shading Envelopes generated in this case is 16 solutions (Fig. 7).

\section{Conditions of Satisfaction of the Solar Control Box Constraints}

The Shading Envelope and the Solar Envelope are two minimum and maximum limits of the Solar Control Box XB. Solutions of the XB being over the Shading Envelope ensure shading during the overheating hours in summer. Solutions of the XB being under the Solar Envelope ensure solar access during beneficial hours of sunlight in winter.

We conduct here a research of the conditions of 
solar and shading constraints satisfaction. We distinguish then two cases of satisfaction: (a) A total satisfaction: the constraints of the Solar Envelope and the Shading Envelope are totally satisfied.

\begin{tabular}{|c|c|c|c|c|c|}
\hline & & \multicolumn{4}{|c|}{ Variation of the solar cut-off-time } \\
\hline & & $\begin{array}{l}\mathrm{T}_{\mathrm{s} 1}= \\
{[5 \mathrm{~h} 20 \rightarrow 10 \mathrm{~h}] \mathrm{U}[14 \mathrm{~h} \rightarrow 19 \mathrm{~h}} \\
40]\end{array}$ & $\begin{array}{l}\mathrm{T}_{\mathrm{s} 2}= \\
{[5 \mathrm{~h} 20 \rightarrow 9 \mathrm{~h}] \mathrm{U}[15 \mathrm{~h} \rightarrow 19 \mathrm{~h} 4} \\
0]\end{array}$ & $\begin{array}{l}\mathrm{T}_{\mathrm{s} 3}= \\
{[5 \mathrm{~h} 20 \rightarrow 8 \mathrm{~h}] \mathrm{U}[16 \mathrm{~h} \rightarrow 19 \mathrm{~h} 4} \\
0]\end{array}$ & $\begin{array}{l}\mathrm{T}_{\mathrm{s} 4}= \\
{[5 \mathrm{~h} 20 \rightarrow 7 \mathrm{~h}] \mathrm{U}[17 \mathrm{~h} \rightarrow 19 \mathrm{~h} 4} \\
0]\end{array}$ \\
\hline \multirow{4}{*}{$\begin{array}{l}\text { Variation of } \\
\text { the solar } \\
\text { fences plane }\end{array}$} & Lvl.0m & $\mathrm{V}=9,023 \mathrm{~m}^{3}$ & $\mathrm{~V}=5,427.41 \mathrm{~m}^{3}$ & $\mathrm{~V}=3,392.7 \mathrm{~m}^{3}$ & $\mathrm{~V}=1,969.04 \mathrm{~m}^{3}$ \\
\hline & Lvl.3m & $\mathrm{V}=10,334.04 \mathrm{~m}^{3}$ & $\mathrm{~V}=6,738.44 \mathrm{~m}^{3}$ & $\mathrm{~V}=4,703.74 \mathrm{~m}^{3}$ & $\mathrm{~V}=3,280.08 \mathrm{~m}^{3}$ \\
\hline & Lvl.6m & $\mathrm{V}=11,645.08 \mathrm{~m}^{3}$ & $\mathrm{~V}=8,049.48 \mathrm{~m}^{3}$ & $\mathrm{~V}=6,017.77 \mathrm{~m}^{3}$ & $\mathrm{~V}=4,591.11 \mathrm{~m}^{3}$ \\
\hline & Lvl.9m & $\frac{\mathrm{IN}}{\mathrm{V}=12,956.11 \mathrm{~m}^{3}}$ & $\mathrm{~V}=9,360.51 \mathrm{~m}^{3}$ & $\mathrm{~V}=7,325.81 \mathrm{~m}^{3}$ & $\mathrm{~V}=5,902.15 \mathrm{~m}^{3}$ \\
\hline
\end{tabular}

Fig. 7 Generation of the Shading Envelopes for an isolated habitat parcel located in Tozeur (Tunisia).

\begin{tabular}{|c|c|c|c|c|}
\hline & $\begin{array}{l}\text { Conditions of } \\
\text { constraints } \\
\text { satisfaction }\end{array}$ & SE and $\mathrm{OE}$ & SE and OE constraints & Generation domain of XB \\
\hline $\begin{array}{l}\text { Total } \\
\text { satisfaction } \\
\text { domain }\end{array}$ & $\begin{array}{l}S E>O E \\
\text { and } \\
O E \quad S E\end{array}$ & & $\begin{array}{l}\text { SE constraints } \\
\mathrm{T}_{\mathrm{o} 3}=[11 \mathrm{~h}-13 \mathrm{~h}] \\
\mathrm{P}_{\mathrm{co}}=\text { Lvl. } 6 \mathrm{~m} \\
\mathrm{OE} \text { constraints } \\
\mathrm{T}_{\mathrm{s} 3}=[5 \mathrm{~h}-8 \mathrm{~h}] \mathrm{U}[16 \mathrm{~h}-19 \mathrm{~h} 40] \\
\mathrm{P}_{\mathrm{cs}}=\text { Lvl. } 3 \mathrm{~m}\end{array}$ & $\begin{array}{l}\text { Privileged domain for the } \\
\text { establishment of urban } \\
\text { rules of solar control. }\end{array}$ \\
\hline
\end{tabular}




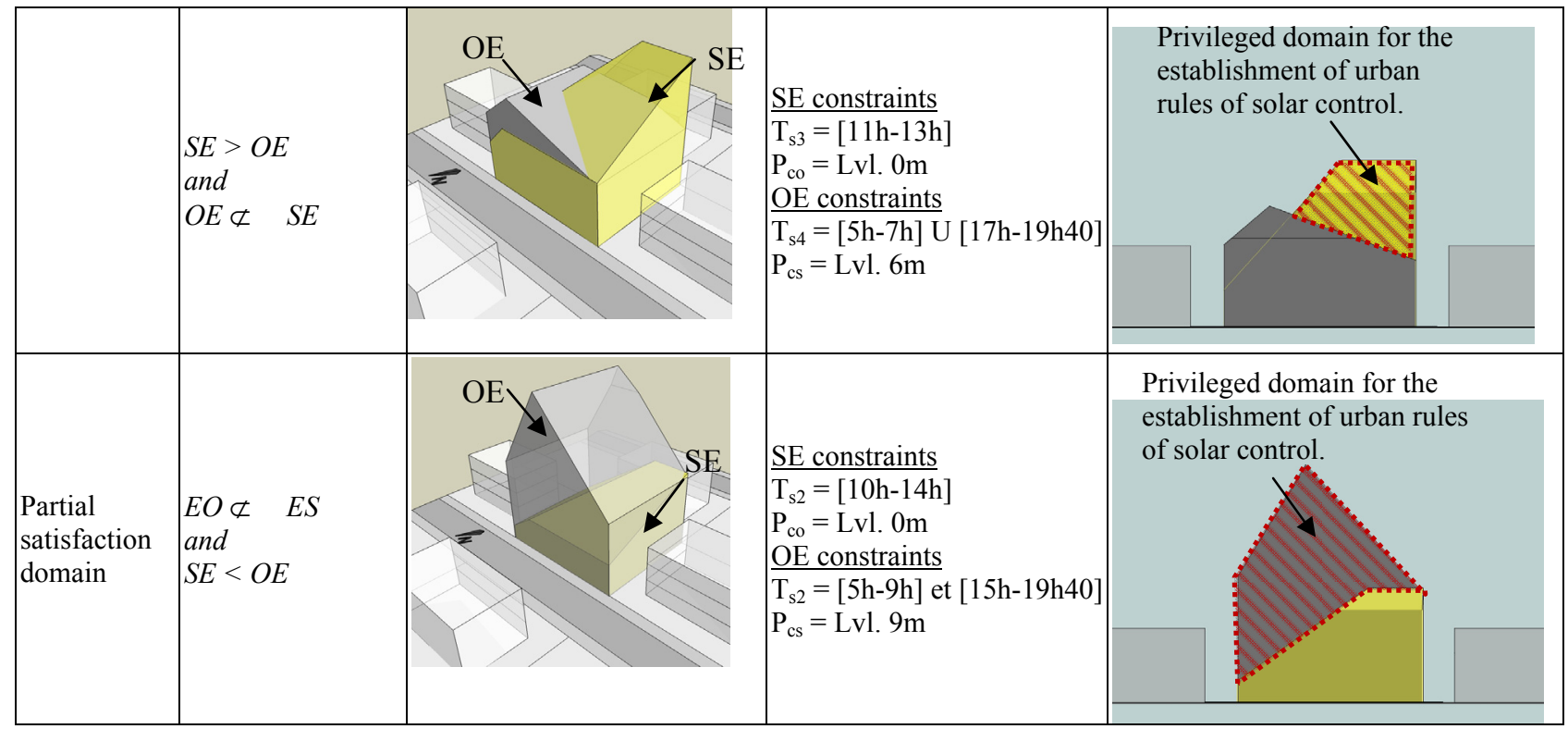

Fig. 8 Conditions of satisfaction of the Solar Control Box constraints.

To achieve this goal, both Solar and Shading Envelopes must satisfy the following condition: $S E>$ $O E$ with $O E \subset S E$ or $O E \not \subset S E$. This condition allows defining a total satisfaction domain for the generation of the XB solutions. This domain is located over the Shading Envelope and under the Solar Envelope (Fig. 8). The domains situated over the Solar Envelope and under the Shading Envelope do not allow total satisfaction of the constraints. The interstitial domain between the Solar Envelope and the Shading Envelope is then a privileged domain for the establishment of urban rules for solar control.

(b) A partial satisfaction: the constraints of the Solar Envelope and the Shading Envelope are partially satisfied. In this case $S E<O E$ and $O E \not \subset$ $S E$. This condition allows defining a partial satisfaction domain for the generation of the XB solutions. This domain is located over the Solar Envelope and under the Shading Envelope (Fig. 8). We note here that the domains situated over the Shading Envelope and under the Solar Envelope have a negative balance of satisfaction of the solar and shading constraints. They are too far from the boundary of the two envelopes. The interstitial domain between the Solar Envelope and the Shading
Envelope is here, the privileged domain for the establishment of urban rules of solar control.

\section{Discussion}

\subsection{Solar and Shading Cut-off-time}

We defined the solar and shading cut-off-time based on monthly average temperatures of the studied area. We then selected the first day of the hottest month to fix solar cut-off-time and the coldest to fix the shading cut-off time. It would be pertinent here to base our research on daily meteorological data, of these two months, to define accurately the days of the year for which a minimum solar access and shade would be most desirable. This will refine the cut-off-time constraints, and consequently the Solar and Shading Envelope according to the real needs of a considered region.

\subsection{Satisfaction of the Constraints}

We set two domains of satisfaction of the solar access and the shading constraints: a total satisfaction domain and a partial satisfaction domain. To achieve total satisfaction of constraints, Solar Envelope must be larger than the Shading Envelope $(S E>O E)$. The Solar Envelope is larger when the shading 
cut-off-time is reduced (Fig. 8). Then, total satisfaction of solar access and shading constraints would be easier to achieve in hot climates where solar access need is minimal compared to shading need.

In the partial satisfaction domain, the satisfaction of one constraint (solar access or shading constraints) implies not meeting the other constraint (solar access or shading constraints).

In this case, the more the $\mathrm{XB}$ solutions are approaching the limit of the Shading Envelope the more they will cast shadows. On the other hand, the more the XB solutions are approaching the limit of the Solar Envelope the more they will provide solar access. It would be useful here to measure the satisfaction degree of the constraints according to the proximity of a solution to the limit of the Solar Envelope or the Shading Envelope. This would allow identifying the optimal XB solutions according to the solar access or shading need and depending on climatic characteristics of a considered region.

\section{Conclusion}

The main object of this paper is to present the conditions of satisfaction of the Solar Control Box constraints. We have seen how the concept the Solar Control Box would be efficient to determine solutions with relatively contradictory constrains. This concept opens new perspectives for the establishment of urban rules respecting the particular climatic context of each region.

\section{Acknowledgments}

The authors would like to thank M2A Team of the National School of Architecture and Urbanism of
Tunisia, where the idea was originally conceived as part of the thesis.

\section{References}

[1] Raboudi, K., and Ben Saci, K. 2014. "Génération de volumes de contrôle solaire." Chez interaction(s) des maquettes numériques: Acte du Séminaire de Conception Architecturale Numérique (SCAN'14), Luxembourg, PUN-Editions Universitaires de Lorraine.

[2] Twarowski, M. 1967. Soleil et Architecture. Paris: Dunod.

[3] Achard, P., and Gicquel, R. 1986. The European Passive Solar Handbook. Bruxelles: Commission of the European Communities.

[4] Siret, D. 1997. "Propositions pour une approche déclarative des ambiances dans le projet architectural : Application à l'ensoleillement." Nantes.

[5] Knowles, L. R. 1981. Sun Rhythm Form. Cambridge: MIT Press.

[6] Pereira, F. O. R., and Nome Silva, C. A. 1998. "A Proposal for the Implementation of the Solar Envelope in Urban Planning as a Concept for Regulating the Occupation of Urban Area." Paper presented on PLEA 98: The 15th International Conference on Passive and Low Energy Architecture, Lisbon, Portugal.

[7] Casabianca, G., Evans, J. M., and Schiller, S. 1991. "Solar Right and Planning Codes." Paper presented on PLEA'91-The 9th International Conference on Passive and Low Energy Architecture, Sevilla.

[8] Raboudi, K., and Ben Saci, A. 2013. "A Morphological Generator of Urban Rules for Solar Control." In Proceedings of the 29th International PLEA Conference, 6.

[9] Stasinopoulos, T. N. 2000. "Solar Envelope: A Construction method using AutoCAD 2000." http://www.ntua.gr/arch/geometry/tns/solenvelope/. 